\title{
Molecular characterization and phylogenetic analysis of Toxocara species in dogs, cattle and buffalo in Egypt
}

\author{
O. A. MAHDY ${ }^{1, *}$, W. M. MOUSA ${ }^{1}$, S. Z. ABDEL-MAOGOOD' ${ }^{1}$, S. M. NADER ${ }^{2}$, S. ABDEL-RADI ${ }^{1}$ \\ 1'Department of Parasitology, Faculty of Veterinary Medicine, Cairo Univ. Giza, Egypt, "E-mail: dr.olfat.mahdy@cu.edu.eg; \\ ${ }^{2}$ Department of Zoonoses, Faculty of Veterinary Medicine, Cairo Univ. Giza, Egypt
}

Article info

Received May 20, 2019

Accepted December 21, 2019

\section{Summary}

Toxocara canis of dogs and Toxocara vitulorum of cattle and buffalo are nematode parasites that cause serious economic and public health problems all over the world. This study aims to provide molecular data to identify and distinguish between Toxocara spp. from dogs, cattle and buffalo in Egypt. Moreover, constructing a phylogeny and phylogenetic relationships among these Toxocara spp. were performed through an analytic study of ATPase-6, a mitochondrial gene; $12 \mathrm{~S}$, small subunit ribosomal RNA gene and ITS-2, the second internal transcribed spacer nuclear ribosomal gene. T. vitulorum from cattle and buffalo were found to be almost identical. The ATPase- 6 and $12 S$ regions showed $87.78 \%$ and $90.38 \%$ nucleotide similarity between $T$. canis and $T$. vitulorum, while for the ITS-2 region, only $78.38 \%$ was found. Analysis of the three studied genes revealed that each Toxocara spp. has distinct molecular characteristics. Moreover, it was revealed that these genes, especially the ITS-2 gene, are useful and sensitive molecular markers for classifying and studying the phylogenetic analysis and relationships among closely related Toxocara spp. All sequences obtained in this study were registered in the GenBank under the accession numbers: MG214149 -MG214157. Keywords: Toxocara vitulorum; T. canis; molecular characterization; PCR-mitochondrial gene- ribosomal gene; dogs; cattle; buffalo; Egypt

\section{Introduction}

Toxocara vitulorum is a nematode parasite of the small intestine of cattle and buffalo, particularly young calves that causes high morbidity and mortality Dorrny et al. (2015). These calves are infected when they suckle colostrum/milk contaminated with infective larvae from infected adult buffalo, Starke-Buzetti and Ferreira (2006). Moreover, T. canis is a zoonotic parasite that can cause serious diseases in dogs and humans. T. canis is usually found in 2 weeks to 2 months old puppies, which can be infected via the placenta (major route) or milk of the mother (minor route), Rahbarm et al. (2013). Migration of larvae through tissues produces severe inflammatory reactions and, consequently, a wide range of pathological and clinical manifestations, Joy et al. (2017).

The low economic status and lack of knowledge of farmers in tropical and subtropical countries that drink raw cattle or buffaloes' milk (Rast et al., 2013) are likely to accelerate the transmission of the parasite, which causes visceral larval migrans (VLM) in the human body. Additionally, poor hygiene, poor sanitation and close contact with dogs lead to the transmission of $T$. canis, Borecka et al. (2010). Coprological examination techniques fail to detect prepatent infections in adult buffalo and mild infections in young calves, Jyoti et al. (2011). Generally, there are limitations for diagnosing of Toxocara infections depending on morphological characters of its

\footnotetext{
$\bar{*}$ - corresponding author
} 
eggs or by using traditional serological methods. Nowadays, PCR considered being a valuable molecular diagnostic method that could be used for accurate identification of infection in different hosts. Therefore, it is critical to develop specific identification using molecular characterization methods, such as PCR-based techniques utilizing a range of genetic markers in the nuclear and mitochondrial genomes; these techniques are useful approaches to determine the genetic composition and phylogenetic relationships with high sensitivity, specificity, rapidity and utility, Chen et al. (2012). This aimed to assist ordinary diagnosis, understanding epidemiology and control of parasitic infections in the medical and veterinary sciences, Li et al. (2016). VLM diagnosed in Egypt still an open question as it caused by Toxocara species of canine or bovine origin, with the intimate morphological similarity between $T$. vitulorum extracted from cattle and buffalo, the disease is more common and dangerous in buffalo calves than in cattle one. According to the Egyptian conditions, the probability of infection by VLM in humans by Toxocara species from dogs or bovine sources is equal to the level of the rural area; the genomic study still required to investigate the source of infection to human. In this respect several authors, such as Zhu et al. (2000) in Australia, Wickramasinghe et al. (2009) in Sri Lanka, Jeeva et al. (2014) in India, and Oguz et al. (2018) in Turkey have investigated the value of using the sequences of ITS-1, ITS-2 and ATPase-6, 12S, 28S genes in the identification of Toxocara spp.

Furthermore, studies by Mikaeili et al. (2015) in Iran and Oguz (2018) in Turkey demonstrate the value of the mitochondrial cytochrome c oxidase subunit I (cox1) gene in the identification of $T$. vitulorum from cattle calves. Regarding Oguz et al. (2018), existing keys and PCR sequencing of the ITS-2 fragment were used to identify the phylogenetic tree of $T$. canis from stray dogs in Turkey. With significant variations in pathogenicity and destitution of $T$. vitulorum infection between cattle and buffalo calves in Egypt, no previous studies in this respect concerning the genomic difference between T. vitulorum extracted from two different hosts; cattle and buffalo as well as its computability or differences with that extracted from dogs. In Egypt, Sultan et al. (2015) in the mid-Delta region in Egypt demonstrate the amplified sequenced of $T$. vitulorum (cattle origin only) used ITS-1 and 18S genes of ribosomal DNA and constructed the phylogenetic trees of the obtained results without register to their sequenced products in GenBank.

Therefore, the objective of this study was to perform molecular characterization to identify and distinguish between the two closely related Toxocara spp. (T. canis and T. vitulorum) obtained from different definitive hosts (dogs, cattle and buffalo-calves) in Egypt. Through this study, ATPase-6, a mitochondrial gene, 12S, small subunit ribosomal RNA gene and ITS-2, the second internal transcribed spacer nuclear ribosomal gene were used. Moreover, phylogenetic analysis constructed the phylogenetic trees and compared them with nucleotide sequences for obtained Toxocara spp. The results of this study will provide new molecular data to support the study of the evolution and genetic diversity of Toxocara spp. concerning their different definitive hosts. The first published from Egypt of obtained sequences has been registered in the GenBank for future use by the scientific community.

\section{Materials and Methods}

All study steps and experimental procedures were approved by the Institutional Animal Care and Use Committee (CU-IACUC number II AS1516) of Cairo University.

\section{Collection and preparation of samples}

Intact, active 20 Toxocara vitulorum adult worms were collected from the intestine of freshly slaughtered buffalo and cattle calves from Cairo abattoir. While, seven adult $T$. canis worms were collected from naturally infected stray puppies (3weeks -3 months age), from Cairo governorate harbor eggs in their feces. The isolated ascarids nematodes specimens were washed extensively in phosphate buffered saline (PBS) to remove any debris and then were fixed in $70 \%$ ethanol, cleared in lacto-phenol, permanent mount in glycerol and identified by microscopy as $T$. canis and $T$. vitulorum according to existing keys Soulsby (2012). After that, the parasites were fixed in $70 \%$ ethanol. Other adults Toxocara species worms $(n=3)$ from each $T$. vitulorum (cattle, buffalo) and T.canis of dogs origin were frozen at $-20{ }^{\circ} \mathrm{C}$ until extraction of genomic DNA.

\section{DNA extraction}

DNA was extracted from a small portion of specimens of adult $T$. vitulorum and T. canis samples using QIA amp DNA Mini Kit (Qiagen, $\mathrm{GmbH}$, Hilden, Germany) following the procedures recommended by the manufacturer.

\section{DNA amplification}

Amplification was performed using conventional PCR assays, according to the methods of Casiraghi et al. (2001).

The analysis was performed according to Wickramasinghe et al. (2009) using the listed primers' sequences in standard PCR procedures for amplification of the mitochondrial gene (ATPase-6, including the partial sequence of NAD1 and NAD2 genes), 12S gene (the small subunit ribosomal RNA) and ITS-2 nuclear ribosomal gene.

$\begin{array}{ll}\text { Primer } & \text { Sequence } \\ \text { nema ATPase-6F } & \text { 5'-TWYCCWCGTTWTCGTTATGA-3' } \\ \text { nema ATPase-6R } & \text { 5'-CTTAAAACAAATRCAYTTMT-3' } \\ \text { 12SF } & \text { 5'-GTTCCAGAATAATCGGCTA-3' } \\ \text { 12SR } & \text { 5'-ATTGACGGATGAGTTTGTACC-3' } \\ \text { Forward primer 3S } & \text { 5'-CGGTGGATCACTCGGCTCGT-3' } \\ \text { Reverse primer 28A } & \text { 5'- CCTGGTTAGTTTCTTTTCCTCCGC-3' }\end{array}$

$P C R$ was carried out in a final reaction volume of $25 \mu$. The amplifications were performed with $5 \mu$ l of DNA extract, $12.5 \mu \mathrm{l} \mathrm{Taq \circledR}$ Green Master Mix, $5.5 \mu \mathrm{l}$ of nuclease-free water and $1 \mu \mathrm{l}$ of each forward and reverse primer. The amplification program was carried 
out in MyCycler ${ }^{\mathrm{TM}}$ thermal cycler (BioRad, USA) with 3 min of initial denaturation at $94^{\circ} \mathrm{C} ; 31$ cycles of $30 \mathrm{~s}$ at $94^{\circ} \mathrm{C} ; 30 \mathrm{~s}$ at $46^{\circ} \mathrm{C}$ and $1 \mathrm{~min}$ at $72^{\circ} \mathrm{C}$; followed by a final 5 minextension at $72^{\circ} \mathrm{C}$ for all primers except the $12 \mathrm{~S}$ and ITS-2 primers, for which annealing was performed at $50^{\circ} \mathrm{C}$ and $53^{\circ} \mathrm{C}$, respectively. The nine amplified PCR products were visualized via agarose gel electrophoresis and the molecular weight (M.W.) of each band was calculated using a $100-1500$ bp DNA ladder. The obtained gel was examined under a transilluminator and photographed.

\section{DNA sequencing}

The PCR products of the three genes were purified with a QIA quick PCR purification column (Qiagen, $\mathrm{GmbH}$, Hilden, Germany), and then the purified products were sequenced with an $A B I$ 3730XL DNA sequencer using a Sequencing Clean-Up kit.

\section{Sequence alignments and phylogenetic analysis}

The obtained sequences were introduced into the NCBI Basic Local Alignment Search Tool (BLAST) for searching of sequence similarity for each one then; all sequences were aligned using BIOEDIT software and CLUSTAL W application. Phylogenetic analysis was performed using the MEGA program and the neighbor-joining method was performed to obtain phylogenetic trees which estimated by performing 1000 bootstrap replicates. The sequences were submitted to the GenBank following the provided instructions.

\section{Results}

The ascarids of both species Toxocara nematodes; T. canis and T. vitulorum were identified microscopically based on morphological features. Toxocara vitulorum is a large, robust worm up to 25 $\mathrm{cm}$ long with three large, prominent lips. The body was soft and translucent with clearly cuticle (Fig.1A - B). Male and females were ranged from $17.51(15.54-19.00 \mathrm{~cm})$ and $22.93(19.32$ $29.11 \mathrm{~cm}$ ) in average length, and $0.5-0.65 \mathrm{~mm}$ (mean $0.6 \mathrm{~mm}$ ) in width, respectively. The three well defined lips; two subventral and one dorsal lip were determined from the worms (Fig.1D). The male worms had a posterior end curved ventrally (Fig.1B). The male posterior end exhibited two spicules, post cloacal papillae and the bell_ shaped projection were observed (Fig.1G). While, in female posterior end was distinguishable a straight-tailed (Fig.1F). Toxocara canis revealed a cephalic alae in the anterior region in both sex. The male worms had a posterior end coiled. The tail was conical and reached $0.89-1.3 \mathrm{~mm}$ (mean $1.1 \mathrm{~mm}$ ) long. The spicules were equal, and reached $2.9-3.3 \mathrm{~mm}$ (mean $3.1 \mathrm{~mm}$ ) long. In females, the cervical alae measured $3.2-3.9 \mathrm{~mm}$ in length and $0.22-0.32 \mathrm{~mm}$ (mean $0.34 \mathrm{~mm}$ ) in width. In female worms, the uterus occupied $2 / 3$ of the body, and contained many eggs. The eggs were measured $70-80 \mu m$ (mean $75.5 \mu m, n=10$ ) in diameter, rounded in shape and brown in color. It contained a single-cell embryo, and had a thin shell with an aluminous surface which is finely mammilated.
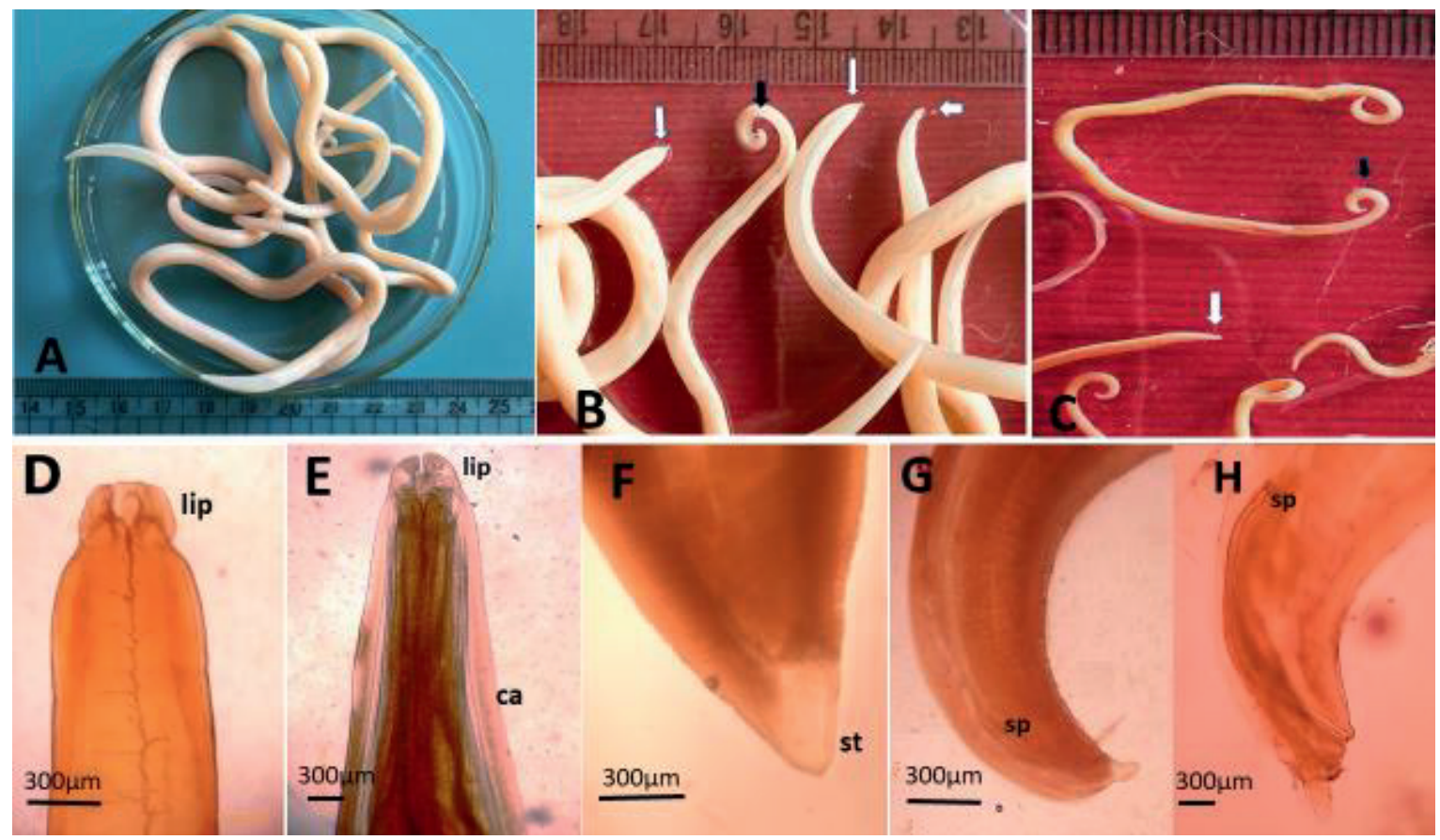

Fig. 1. A - B. Toxocara vitulorum collected from calves. B) Anterior end of worm showed lips (short white arrow), posterior end of male showed coiled tail (black arrow), and posterior end of female worm showed a straight tail end (long white arrow). D) Anterior end of T.vitulorum showed three lips (lip), F) posterior end of female showed short tail (st), G) posterior end of male showed two spicules (sp), C) Toxocara canis collected from street dogs; showed the coiled tail-end of male (black arrow), the straight tail-end of female (white arrow), E) Anterior end of T. canis showed the cephalic alae and lips, F) posterior end of male showed spicules. 
Table 1. Characterization of the PCR products of the selected genes in the tested Toxocara spp. showing the M. W. of the bands for each gene.

\begin{tabular}{cccc}
\hline \multirow{2}{*}{ Gene } & \multicolumn{3}{c}{ M.W. (bp) } \\
\cline { 2 - 4 } & T. canis & T. vitulorum from cattle & T. vitulorum from buffalo \\
\hline ATPase-6 & 804 & 828 & 828 \\
12S & 572 & 576 & 572 \\
ITS-2 & 592 & 625 & 625 \\
\hline
\end{tabular}

The data in Table 1 and Plate 1 show the results of agarose gel electrophoresis of the nine PCR products of the three worms from each tested Toxocara spp.; T. canis (dogs) and T. vitulorum (cattle and buffalo-calves). The ATPase- 6 gene of $T$. canis produced a $804 \mathrm{bp}$ band, while that of $T$. vitulorum from both cattle and buffalo calves produced 828 band bp. Electrophoretic analysis of the $12 \mathrm{~S}$ gene showed bands of M.W.572, 576 and 572 bp for T. canis, T. vitulorum from cattle and $T$. vitulorum from buffalo respectively. Moreover, analysis of the ITS-2 gene revealed a band of M.W. 592 bp for $T$. canis. While a band of $625 \mathrm{bp}$ was detected for $T$. vitulorum from both cattle and buffalo-calves.

\section{ATPase-6 gene}

Analysis of the ATPase- 6 gene revealed that the sequences of this gene in $T$. canis of dogs and $T$. vitulorum from cattle and buffalo-calves were $G / T$ rich. Moreover, the length of the nucleotide sequence in $T$. canis was $600 \mathrm{bp}$, while that in $T$. vitulorum from both cattle and buffalo-calves was $598 \mathrm{bp}$.

A phylogenetic tree constructed by the neighbor-joining method for the ATPase-6 region. There was $99.16 \%$ identity in this gene between the tested $T$. vitulorum specimens from cattle and buffalo-calves in the present study, while $87.78 \%$ identity was detected between the tested T. canis and T. vitulorum specimens from Egypt. Additionally, it was revealed that the $T$. vitulorum from buffalo-cattle calves (MG214154.1) in the current study was closely related to $T$. vitulorum from in India (KJ777176.1), with $99.50 \%$ identity to that in Sri Lanka (FJ418793.1) with $99.33 \%$ identity. Moreover, the sequence for T. canis in the current study was $100 \%$ identity to that T. canis isolated in India (KJ777174.1) While, with $99.67 \%$ identity to T. canis isolated in Sri Lanka (FJ418787.1), Plate 2.

\section{S rRNA gene}

The data showed that the lengths of the $12 S$ gene sequences obtained from $T$. canis (dogs), T. vitulorum (cattle-calves) and $T$. vitulorum (buffalo-calves) were 493, 464 and 465 bp, respectively. Moreover, the sequences of this gene in the tested Toxocara spp. were found to be A/T rich.

Concerning the phylogenetic tree constructed for the 12S gene, 98. $01 \%$ identity was observed between the tested T. vitulorum from buffalo origin and cattle origin in the present study, while $90.38 \%$ identity was detected between the tested $T$. canis and T. vitulorum isolated in Egypt. Also, T. vitulorum from buffalo (MG214157.1) in Egypt was found to be closely related to $T$. vitulorum isolated in Sri Lanka (FJ418789.1), with $97.22 \%$ identity. The gene sequence in T. vitulorum from cattle (MG214156.1) in the current study was $99.35 \%$ identity to $T$. vitulorum isolated in India (KJ777171.1 - KJ777172.1). Moreover, the sequence in $T$. canis (MG214155) from Egypt in the current study was closely related $100 \%$ identity to that from Sri Lanka (FJ418782.1), China (JN256964.1) and in India (KJ777168.1) and Plate 3.

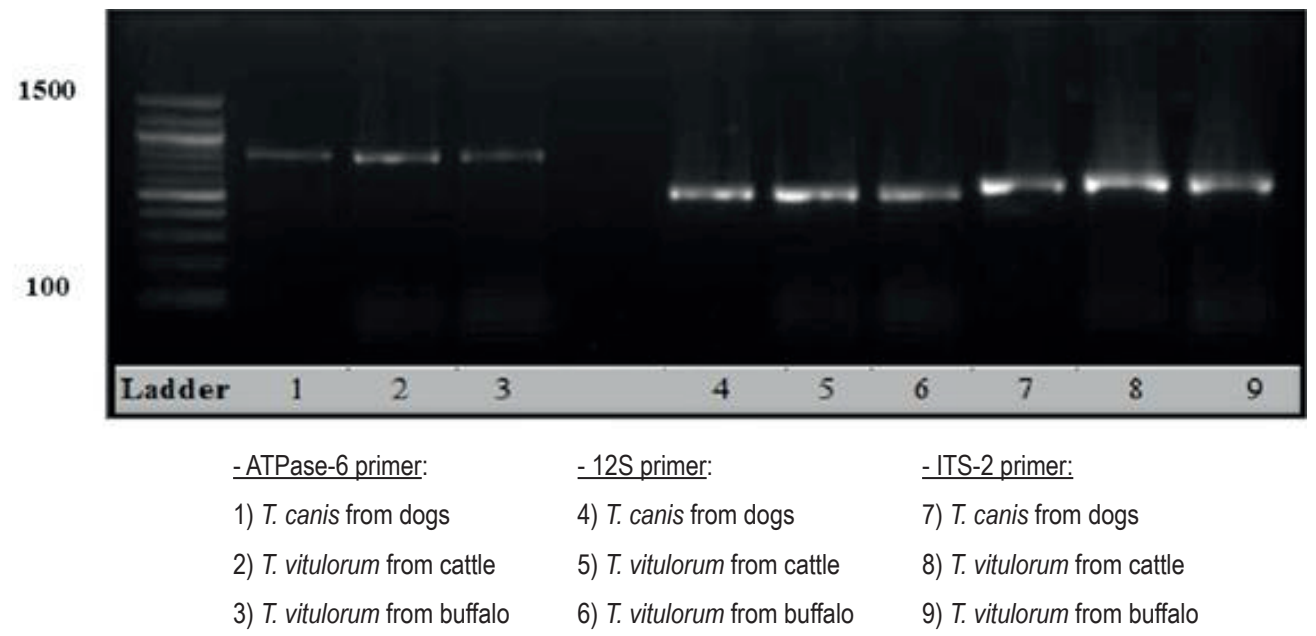

Plate 1. Results of agarose gel electrophoresis of the PCR products of the selected genes in Toxocara spp. showing the M. W. of each gene band. 


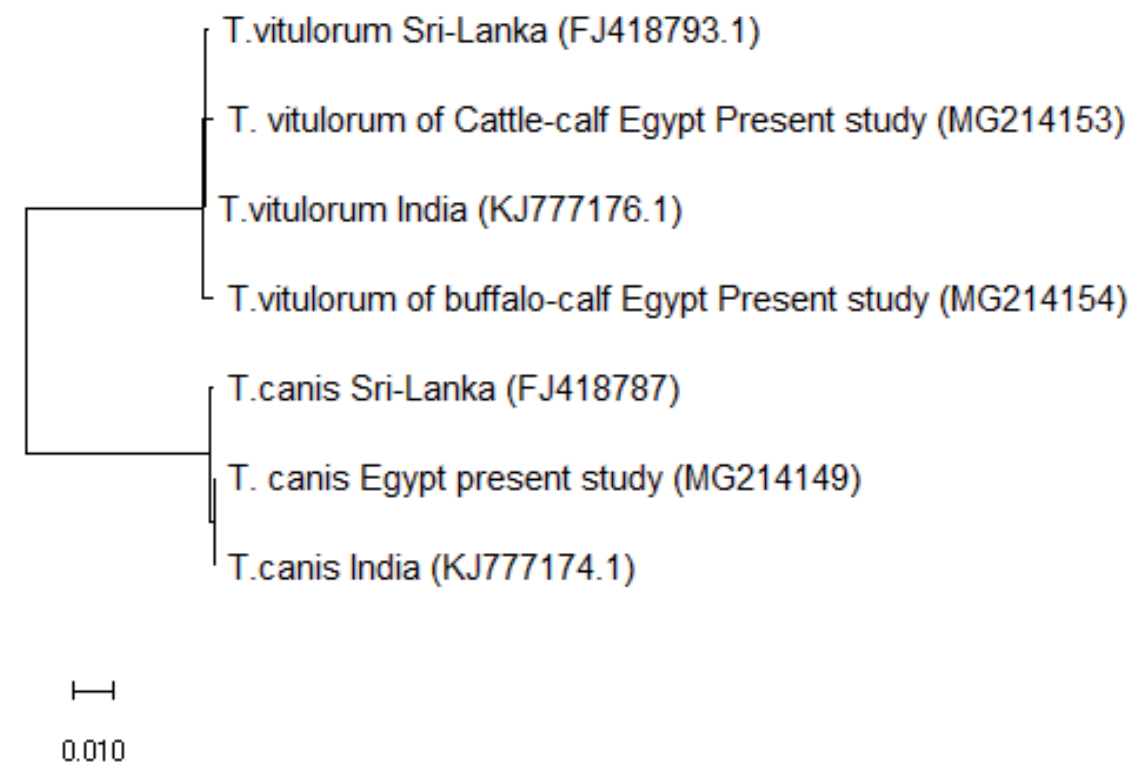

Plate 2. Phylogenetic tree constructed in MEGA by neighbor- joining method for the ATPase-6 region of the tested Toxocara spp.

ITS-2 gene

Analysis of the ITS-2 gene showed that the lengths of nucleotide sequences were 503,532 and $537 \mathrm{bp}$ for $T$. canis, T. vitulorum cattle and buffalo, respectively. Moreover, the sequences of this gene in the tested Toxocara spp. were found to be $A / T$ rich. Regarding the phylogenetic tree constructed for the ITS-2 region, cleared that T. vitulorum of cattle origin and buffalo origin calves was $95.50 \%$ identity. While they were detected $78.38 .0 \%$ identity between $T$. canis and $T$. vitulorum buffalo origin and $80.79 \%$ identity between $T$. canis and T. vitulorum from cattle origin in Egypt. This result indicates that the ITS-2 gene appeared to be a good sensitive tool for the identification of adult worms of Toxocara spp. The phylogenetic tree distinctly separated the ITS-2 sequences gene of $T$. vitulorum group from that of $T$. canis into two major lineages.

It was revealed that $T$. vitulorum of cattle origin (MG214151.1) was found to be closely related to that in Canada (JQ083352.1) with $99.77 \%$ identity. Concerning had $95.5 \%$ identity with buffalo in Egypt (MG214152.1) and Sri Lanka (FJ418784.1). Toxocara vitulorum isolated from cattle in India (KJ777159.1) and Scotland (EU189085.1) with $97.38 \%$ and $99.43 \%$ identity.

Moreover, T. canis in Egypt (MG214150.1) was found with $100 \%$ identity to that in India (KJ777155.1 \& MK728992.1), in Japan

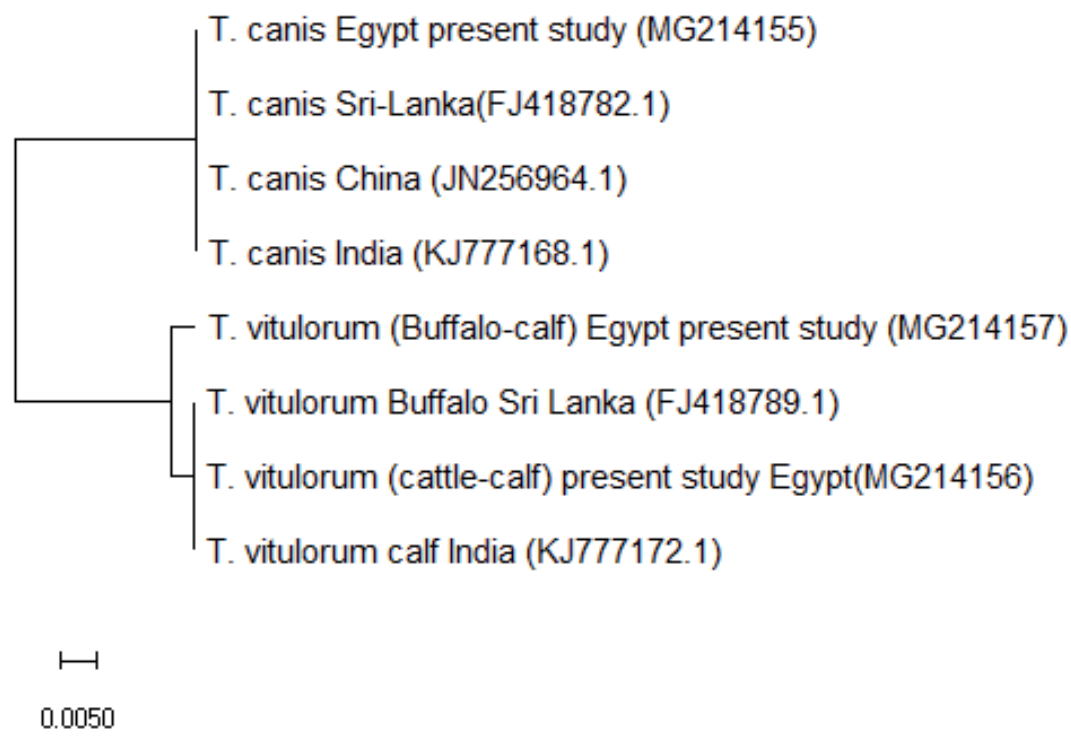

Plate 3. Phylogenetic tree constructed in MEGA by neighbor-joining method for the $12 \mathrm{~S}$ region of the tested Toxocara spp. 


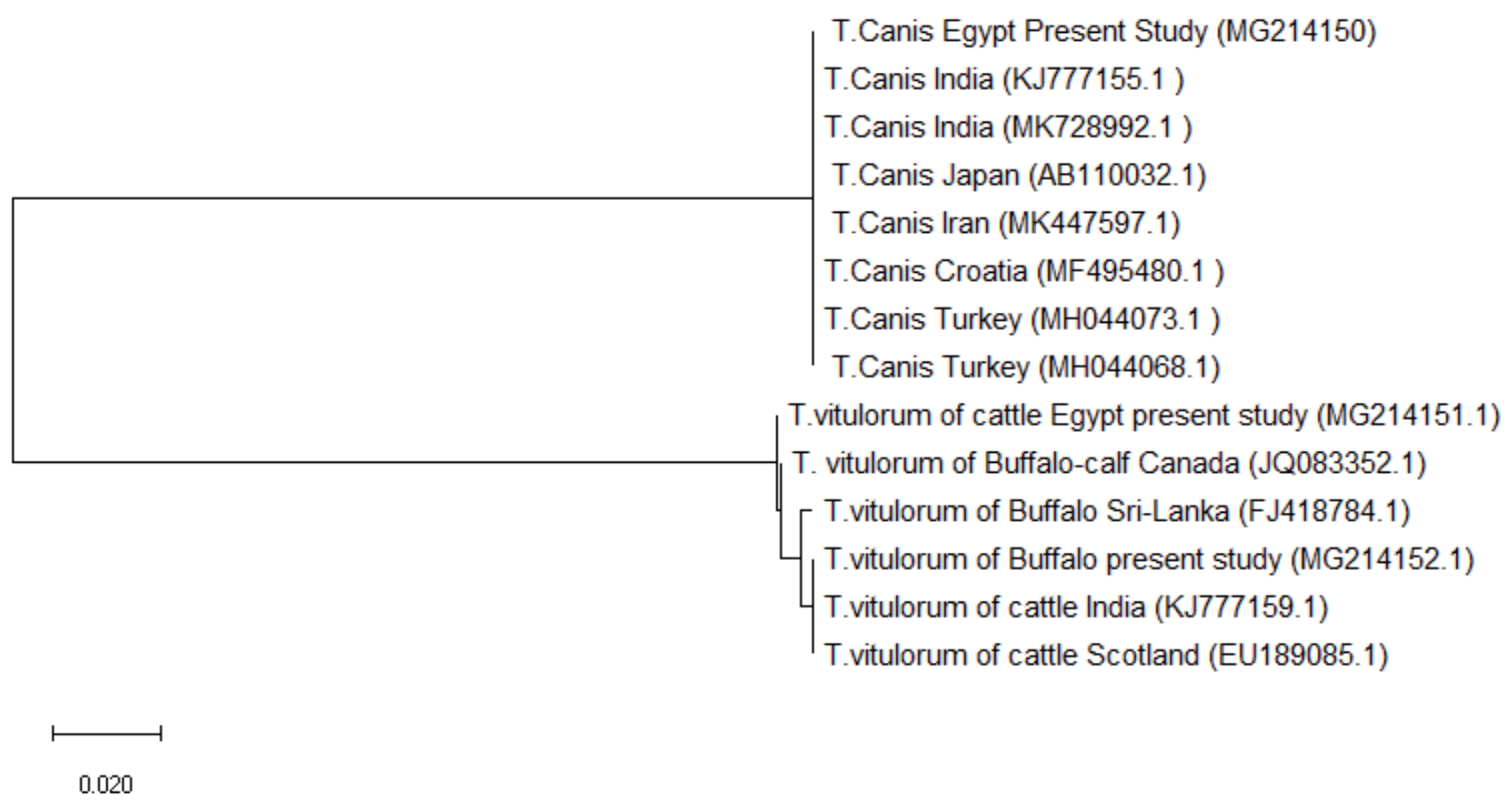

Plate 4. Phylogenetic tree constructed in MEGA by neighbor- joining method for the ITS-2 region of the tested Toxocara spp.

(AB110032.1), in Iran (MK447597.1), in Croatia (MF495480.1), in Turkey (MH044073.1 \& MH044068.1), Plate 4. All generated sequences were registered in the GenBank database for the first time in Egypt with accession numbers including, MG214149 MG214157.

\section{Discussion}

T. canis and T. vitulorum are nematode parasites that cause serious problems in dogs, cattle and buffalo, Strub et al. (2013). With the grate morphological difference between canine and bovine species, Soulsby (2012), the morphological characters of their diagnostic stages (their eggs) are similar. In a time where no clear morphological differences between $T$. vitulorum extracted from infected cattle or buffalo calves, the incidence and pathogenicity of them considered to be dangerous in buffalo than in cattle on the level of the same localities (Fagiolo et al. 2007). With the presence of recorded cases of VLM in humans who are in close contact with these animals, no accurate determination to genotypic data support the ability of Toxocara of bovine origin to cause problems similar to that previously caused by Toxocara of dog origin from the aspect of VLM in human. Due to the limitations of traditional (morphological and corpological) approaches for the identification of Toxocara spp. and the diagnosis of related infections, it was essential to develop specific identification criteria using molecular characterization techniques to determine genetic compositions and phylogenetic relationships with high sensitivity, specificity, rapidity and utility, Jyoti et al. (2011) and Chen et al. (2012). Two common species of Toxocara present in Egypt (T. canis and
T. vitulorum) infect three widely distributed hosts (dogs, cattle \& buffalo). Its eggs and larval stages were disseminated in feces and milk and considered to be easily transferred to humans. With the known data about the ability of $T$. canis larvae to cause VLM in humans, are the other species ( $T$. vitulorum) that can do the same. With difficulty in proving this on the human level, the present study directed toward determine molecular and phylogenetic compatibility between them. The recent studies in Turkey by Oguz and Oguz et al. (2018) demonstrate the value of the mitochondrial cytochrome $c$ oxidase subunit I (cox1) gene of $T$. vitulorum from cattle calves and ITS-2 fragment of $T$. canis from dogs were used to identify the morphological gene in identification, respectively. In this respect, DNA-based approaches have been applied to identify the nematode species, mainly using ITS fragments (rDNA) Li et al. (2006) and Fogt-Wyrwas et al. (2013). Sultan et al. (2015) in the mid-Delta region in Egypt demonstrate the amplified sequenced of T. vitulorum (cattle origin only) used ITS-1 and 18 S genes of ribosomal DNA and constructed the phylogenetic trees of the obtained results without register to their sequenced products in GenBank. Therefore, in Egypt, the present study was extracted the first genomic DNA of Toxocara species from dogs, cattle and buffalo-calves using mitochondrial ATPase- 6 and ribosomal gene $12 \mathrm{~S}$ and the nuclear ribosomal gene ITS-2 regions were analyzed amplified and all obtained sequences were registered in GenBank. The mitochondrial ATPase- 6 , rather than single gene, to better account for genetic variability in these genomes across different regions of two closely related nematodes; $T$. canis of dog origin and T. vitulorum of cattle, buffalo-calves in Egypt. It is worth noting that the present study in Egypt, is the first to compare between 
$T$. vitulorum from cattle and buffalo calves in addition to $T$. canis to search for any molecular differences between them that may occur due to the presence of the adult worm in the intestine of two different ruminant host.

The sequences of ATPase- 6 gene of $T$. canis and T. vitulorum from cattle and buffalo were found to be $G / T$ rich. While the sequences of the $12 S$ gene and ITS-2 region were found to be rich with A/T - Similar results were reported for Toxocara spp. in Sri Lanka by Wickramasinghe et al. (2009). On the other hand, Hu and Gasser (2006) stated that all mitochondrial genes sequenced in Toxocara spp. are A/T rich.

In the present study, the analysis of the ATPase-6, 12S and ITS-2 genes sequences revealed that the length of the nucleotide sequence in T. canis (600 bp, 493 bp.,503 bp., in T. vitulorum cattle origin; $598 \mathrm{bp}, 464 \mathrm{bp}, 532 \mathrm{bp}$. and in T. vitulorum buffalo origin, 598 bp., 465 bp, 537 bp. respectively. These results were nearly similar to those reported for specimens from Wickramasinghe et al. (2009), who stated that the length of the nucleotide sequence of ATPase- 6 gene in T. canis and T. vitulorum was 597 bp. However, the present results are inconsistent with those of Zhu et al. (2000), who stated that the ITS-2 region ranged from $240-348$ bp long in $T$. canis and $T$. vitulorum from Australia.

In the present study, after alignment of the sequences of the three analyzed genes/regions (ATPase-6, 12S and ITS-2) in T. canis and T. vitulorum from cattle and buffalo in Egypt and in Toxocara spp. from other countries as well as subsequent analysis and construction of a neighbor-joining phylogenetic tree, it was observed that T. vitulorum from both cattle and buffalo formed a single group, as both hosts are ruminants. In contrast, $T$. canis formed a separate group. Each group consisted of several sister clades for each species analyzed, each of which represented a different definitive host. These findings are consistent with those obtained by Li et al. (2006) in China. In addition, they present results stated that the ATPase- $6,12 \mathrm{~S}$ and ITS-2 regions were more conserved $87.78 \%$, $90.38 \%$ and $78.38 \%$, nucleotide similarity between $T$. canis and $T$. vitulorum. While, revealed that the previous regions was more conserved $99.16 \%, 98.01 \%$ and $95.5 \%$ nucleotide similarity between T. vitulorum from cattle and buffalo-calves in Egypt. This result can provide a foundation for accurate identification of $T$. canis and $T$. vitulorum using PCR characterization of $12 \mathrm{~S}$ and ITS-2 region with nucleotide similarity (90.0\% and $78.38 \%$ ).

This result agrees with Wickramasinghe et al. (2009) reported that the nucleotide identity between $T$. canis and T. vitulorum from Sri Lanka was $88.0 \%$ and $85.0 \%$ for the 12 S and ITS-2 gene, respectively.

T. vitulorum were almost genetically identical to those isolated in other countries. These data are consistent with those of Sultan et al. (2015) who amplified, sequenced of T. vitulorum (cattle origin) using ITS- and 18 S genes had $99.0 \%$ identity with $T$. vitulorum (buffalo origin) registered by Wickramasinghe et al. (2009) in Sri Lanka.

Moreover, the obtained presently sequenced concluded that
T. vitulorum isolated from cattle, buffalo calves using the ITS-2 sequences and those other sequences of the same nematode species were previously registered in GenBank were genetically identical to those isolated from beef calf such as Wickramasinghe et al. (2009) in Sri Lanka, Woodbury et al. (2012) in Canada, Jeeva et al. (2014) in India and Redman et al. (2007) in Scotland. Furthermore, presently concluded genetically identical had $100 \%$ identity of $T$. canis from dogs using the ITS-2 sequences and those other sequences of the same nematode species were previously register in GenBank such as Ishiwata et al. (2004) in Japan, Jeeva et al. (2014) in India, Valizadeh and Tahvildar (2019) in Iran, and Oguz et al. (2018) in Turkey.

Concerning, the ATPase- 6 and $12 S$ genes were found to be more conserved ( $87.9 \%$ nucleotide similarity between $T$. canis and T. vitulorum) than the ITS-2 region (78.38 \%). This result is consistent with that recorded by Durant et al. (2012), who stated that analysis of the ITS-2 gene appeared to be a sensitive tool for the identification of adult worms of Toxocara spp.

\section{Conclusion}

This current study was comparing the molecular characterization and phylogenetic analysis of the relationship between closely related species of Toxocara species from three different hosts (dogs, cattle and buffalo) in Egypt. The characterization of the ITS-2 region can provide a foundation for accurate identification of Toxocara species using PCR than ATPase-6, $12 S$ regions. Concerning, the ITS-2 gene appeared to be a sensitive tool for $78.38 \%$ nucleotide similarity between $T$. canis and $T$. vitulorum when compared with ATPase-6, $12 \mathrm{~S}$ regions were found to be more conserved ( $87.78 \%$ and $90.38 \%$ nucleotide similarity). In the present study, the first genomic DNA was extracted using three different genes amplified and register in GenBank for the first time in Egypt.

\section{Conflict of Interest}

The authors have declared no conflict of interest

\section{References}

Borecka, A., Gawor J., Niedworok M., SordyL, B. (2010): Occurrence of Toxocara spp. eggs in household environment of children with diagnosed toxocariasis in Łódź voivodeship. Wiad Parazytol, 56: $141-144$

Casiraghi, M., Anderson, T.J.C., Bandi, C., Bazzocchl, C., Genchl, C.A. (2001): A phylogenetic analysis of filarial nematodes: comparison with the phylogeny of Wolbachia endosymbionts. Parasitology, 122 (1): 93 - 103. DOI: 10.1017/s0031182000007149

Chen, J., Zhou, D., Nisbet, A.J., LI, M.W., Wang, C., Zhu, X. (2012): Advances in molecular identification, taxonomy, genetic variation and diagnosis of Toxocara spp. Infect. Genet. Evol.,12 (7): 1344 - 
1348. DOI: 10.1016/.j.meegid.2012.04.019

Dorny, P., Devleesschauwer, B., Stoliaroff, V., Sothy, M., Chea, R., Chea, B., Sourloing, H., Samuth, S., Kong, S., Nguong, K., Sorn, S., Holl, D., Vercruysse, J. (2015): Prevalence and associated risk factors of Toxocara vitulorum infections in Buffalo and cattle calves in three provinces of central Cambodia. Korean J. Parasitol., 53 (2): 197 - 200. DOI: 10.3347/kjp.2015.53.2.197

Durant, J.F., IRENGe, L.M., Dumont, C., Doucet, J., Losson, B., GalA, T. (2012): Duplex quantitative real-time PCR assay for the detection and discrimination of the eggs of T. canis and T. cati (Nematoda, Ascaridoidea) in soil and fecal samples. Parasit Vectors, 7 (5): 288. DOI: 10.1186/1756-3305-5-288

Fagiolo, A., Roncoroni, C., Lal, O., Borghese, A. (2007): Buffalo Pathologies. Chapter XIII. FAO Regional Office for Europe, Rome. Retrieved from http://www.fao.org/3/ah847e/ah847e04.pdf

Fogt-Wyrwas, R., Mizgajska-Wiktor, H., Pacon, J., Jarosz, W. (2013): Intraspecific variation between the ITS sequences of Toxocara canis, Toxocara cati, and Toxascaris leonina from different host in south-western Poland. J. Helminthol, 87,432 - 442. DOI: 10.1017/S0022149X1200048X

Hu, M., GASSER, R.B. (2006): Mitochondrial genomes of parasitic nematodes progress and perspectives. Trends Parasitol., 22 (2): 78 - 84. DOI: 10.1016/j.pt.2005.12.003

Jeeva, K., Chatteruee, N., Bera, A.K., Maiti, S., Das, P.J., Ram, H., Baneruee, P.S., Goswami, T.K., Mltton, A.P., Aravind, M. Bhuvanapriya, G., Thilagavathi, K., Chamua, J., Islam, S., Ghosh, S.K., Deb, S.M., BHATTACHARYA, D. (2014): Toxocara vitulorum isolate 6 clone 6 ATP synthase subunit 6 gene partial cds; mitochondrial. Direct submission in GenBank: Accession number; KJ777178.1

Ishiwata, K., Shinohara, A., KInpel, Y., Horil, Y., TsuchiYa, K., Nawa, Y. (2004): Identification of tissue-embedded ascarid larvae by ribosomal DNA sequencing. Parasitol. Res., 92: 50 - 52. DOI 10.1007/ s00436-003-1010-7

Joy, A.T., CHRIs, O.I., Godwin, N.C. (2017): Toxocariasis and Public Health: An Epidemiological Review. Glob. J. Infect. Dis. Clin. Res., 3 (1): 28 - 39. DOI: 10.17352/2455-5363.000016

JYOTI, S.N.K., JUYAL, P.D. (2011): Identification and characterization of immunodominant antigen(s) of Toxocara vitulorum in buffaloes (Bubalus bubalis). Vet Arh, 81: $369-378$

LI, K., Lan, Y., LUO, H., Liu, D., Wang, L., Shahzad, M., LI, J., Chamba, Y. (2016): Prevalence, Associated Risk Factors, and Phylogenetic Analysis of $T$. vitulorum Infection in Yaks on the Qinghai Tibetan Plateau, China. Korean J. Parasitol., 54 (5): 645 - 652. DOI: 10.3347/kjp.2016.54.5.645

LI, M.W., ZHu, X.Q., GASSER, R.B., LIN, R.Q., SANI, R.A., LUN, Z.R., JACOBS, D.E. (2006): The occurrence of $T$. malaysiensis in cats in China, confirmed by sequence-based analyses of ribosomal DNA. Parasitol. Res., 99 (5): 554 - 557. DOI: 10.1007/s00436-0060194-z

Mikaelli, F., Mirhendi, H., Mohebali, M., Hosseini, M., Sharbatkhori, M., ZAREI, Z., KIA, E. B. (2014): Sequence variation in mitochon- drial cox 1 and nad 1 genes of ascaridoid nematodes in cats and dogs from Iran. J. Helminthol., 89 (04), 496 - 501.DOI:10.1017I s0022149x14000133

Oguz. B. (2018): Genetic Characterization of Toxocara vitulorum in Turkey by Mitochondrial Gene Markers (cox1). Acta Sci Vet, 46: 1558. DOI: $10.22456 / 1679-9216.83063$

Oguz, B., Ozdal, N., Deger, M.S. (2018): Genetic analysis of Toxocara spp. in stray cats and dogs in Van province, Eastern Turkey. J Vet Res, 62: 291 - 295. DOI: 10.2478/jvetres-2018-0042

Rahbarm, A., AlborzI, A., SelFI, M. (2013): An alternative method for producing $T$. canis second stage larvae from a paratenic host (pigeon) for mRNA extraction purpose. J Parasit Dis, 39 (2): 186 189. DOI: 10.1007/s12639-013-0310-9

Rast, L, Lee, S., Nampanya, S., Toribio, J.A., Khounsy, S., Windsor, P.A. (2013): Prevalence and clinical impact of $T$. vitulorum in cattle and buffalo calves in northern Lao PDR. Trop Anim Health Prod, 45: 539 - 546. DOI: 10.1007/s11250-012-0256-4

REDMAN, E.M., GILLEARD, J.S. (2007): Identification of Toxocara vitulorum in feces of infected cattle in Wales (UK), using ITS1 and ITS2 sequences Direct submission, in GenBank Accession number; EU189085

SoulsBY, E.J.L. (2012): Helminths, Arthropods and Protozoa of domesticated Animals. 7th Edn, East-West Press Private Limited, New Delhi

Starke-Buzetti, W.A., FerreiRa, F.P. (2006): Characterization of Excretory/Secretory Antigen from T. vitulorum Larvae. Ann. N.Y. Acad. Sci., 1026: 210 - 218. DOI: 10.1196/annals.1307.032

Strub, C., Heuer, L., Janecek, E. (2013): Toxocara spp. infections in paratenic hosts. Vet. Parasitol., 193: 375 - 389. DOI: 10.1016/j. vetpar.2012.12.033

Sultan, K., Omarm M., Desouky, A.Y., El-Selfy M.A. (2015): Molecular and phylogenetic study on $T$. vitulorum from cattle in the mid-Delta of Egypt. J Parasit Dis, 39 (3): 584 - 587. DOI: 10.1007/ s12639-013-0373-7

VALIZADEH, M., TAHVILDAR, F. (2019): Toxocara canis isolate I1 5.8S ribosomal RNA gene and interna transcribed spacer 2, partial sequence. Tehran, Iran, Tehran, Tehran 12345, Iran. Direct submission in GenBank: Accession number; MK447597

Wickramasinghe, S., Yatamara, L., Rajapakse, R.P.V.J., Agatsuma, T. (2009): Toxocara canis and T. vitulorum: molecular characterization, discrimination, and phylogenetic analysis based on mitochondrial (ATP synthase subunit 6 and 12S) and nuclear ribosomal (ITS-2 and 28S) genes. Parasitol. Res., 104: 1425 - 1430. DOI: 10.1017/S003118201200056X

Woodbury, M.R., Copeland, S., Wagner, B., Fernando, C., Hill, J.E., Clemence, C. (2012): Toxocara vitulorum in a bison (Bison bison) herd from western Canada. Can. Vet. J., 53(7): 791 - 794

Zhu, X., Gasser, R.B, Jacobs, D. E., Hung, G., Chilton, N.B. (2000): Relationships among some ascaridoid nematodes based on ribosomal DNA sequence data. Parasitol. Res., 86 (9): 738 - 744. DOI.org/10.1007/PL00008561 